\title{
Aminoadipic Semialdehyde
}

National Cancer Institute

\section{Source}

National Cancer Institute. Aminoadipic Semialdehyde. NCI Thesaurus. Code C120012.

An amino acid derivative that is a product of lysine degradation. This metabolite is associated with oxidative stress. Elevated urine levels of aminoadipic semialdehyde (AASA) are seen in patients with AASA dehydrogenase deficiency. 